\title{
Development of tasty marinating kit for tenderization and preservation of beef chuck
}

\author{
A. Sultana*, K. S. Huque and S. M. Amanullah \\ Animal Production Research Division, Bangladesh Livestock Research Institute, \\ Savar, Dhaka-1341, Bangladesh
}

\begin{abstract}
Chuck is the biggest and one of the tougher cut of beef carcass. By improving the tenderness of chuck meat it can have a higher value to the consumer. The study was conducted to know the efficacy of tasty kit (containing 1.2 M sodium chloride, $0.25 \mathrm{M}$ sodium bicarbonate and $0.1 \%$ ascorbic acid) as a meat preservation and tenderization technique during freezing. Beef chucks from four native bulls were collected from a local market and divided into two groups- one was treated with tasty kit and the other kept as control. Both the treated and untreated meats were well packed and kept in freezer at -20 ${ }^{\circ} \mathrm{C}$ for a month. Compared to the untreated group, higher moisture content was found in treated raw and cooked meat $(p<0.05)$. Significantly lower protein content $(p<0.05)$ in treated cooked meat may be resulted from the solubilization of myofibrillar protein by salt and bicarbonate. Treated meat had a higher water-holding capacity $(p<0.05)$, lower drip loss $(p<0.05)$ and lower cook loss $(p<0.01)$. During a sensory test, panellists gave significantly higher values for general appearance $(p<0.01)$, flavour $(p<0.05)$, colour $(p<0.05)$, tenderness $(p<0.01)$, juiciness $(p<0.01)$ saltiness $(p<0.01)$ and overall acceptability $(p<0.01)$. It is suggested that tough chuck meat may be successfully tenderized with the salt-bicarbonate marinating technique before freezing. (Bangl. vet. 2009. Vol. 26, No. 1, 23-30)
\end{abstract}

\section{Introduction}

Freezing has been an excellent preserving technique for meat and its products for long time. The quality and safety of frozen meat depends upon rapid freezing, continuous electricity supply, temperature stability, good freezer management, proper packaging and cleanliness before freezing. Unfortunately most of those points have not been followed in Bangladesh because of ignorance, unawareness, and unavailable materials or techniques. Beef can be preserved well in frozen for about 12 month without preservatives or cryoprotectants, but with poor procedures the quality of meat deteriorates within a few days.

Freezing procedures influence thawing loss, colour and tenderness (Farouk and Swan, 1998; Honikel et al., 1986). Freezing also affects cooking loss (Farouk et al., 2003), which is influenced by meat quality. The effects on nutrient and quality characteristics of meat of $\mathrm{pH}$, freezer storage, thawing and cooking procedures and the interaction between these factors have not been fully elucidated. Such knowledge is a prerequisite for establishing guidelines for the meat processing industry.

\footnotetext{
*Correspondence: E-mail:- sheema_bau@yahoo.com
} 
Cuts of beef vary in their characteristics. The most valued cuts come from the loin and rib areas, which represent only $26 \%$ of the total carcass (Savell and Smith, 2000). However this finding is from US carcasses, and similar information is not available for indigenous cattle in Bangladesh. Chuck is the biggest portion coming from the shoulder part of beef carcass, but due to a lot of connective tissue is the toughest portion. The warner-bratzler shear force value of chuck cut is about $5.2 \mathrm{~kg}$ (Gary and Chris, 2007) and there is a less demand for it in the market. Tenderising would increase consumer demand, at the same time it is necessary to develop techniques for freezing meat well. The present study was undertaken (a) to develop a marinating kit for meat preservation and tenderization; (b) to test its efficacy during freezing; and (c) to measure the nutrient content and quality of meat after marinating and freezing.

\section{Materials and Methods}

Sample collection and preparation

Samples were collected from the chuck portions of indigenous bull carcasses about 2 to 2.5 years of age. Just after slaughtering the animal, the samples were transported to the meat laboratory, and kept at 10 to $12^{\circ} \mathrm{C}$ for about four hours. After removing the fat, ligaments and tendons from the muscles, they were randomly divided into two groups for each of the three replicated experiments. One group was marinated, the control group was not.

Preparation and application of kit solution

The kit was a solution containing $1.2 \mathrm{M}$ sodium chloride, $0.25 \mathrm{M}$ sodium bicarbonate and $0.1 \%$ ascorbic acid. The solution was injected into the meat, with a target of $120 \%$ of original weight.

\section{Preservation of samples}

After marinating the treated samples, both groups of samples were tumbled 200 times by hand, wrapped in plastic paper and preserved at $-20^{\circ} \mathrm{C}$ for one month.

\section{Measurement of nutrients}

The moisture, protein and fat contents of meat samples were determined according to AOAC (1980).

\section{Measurement of $\mathrm{pH}$}

For measuring $\mathrm{pH}, 5 \mathrm{~g}$ samples were minced with a home blender using stirrer for 30 seconds with $10 \mathrm{ml}$ of distilled water in a $20 \mathrm{ml}$ test tube. The $\mathrm{pH}$ of homogenate was measured using an electrical automatic $\mathrm{pH}$ meter (METTLER TOLEDO, MP230, Switzerland). The $\mathrm{pH}$ of frozen meats was measured just after thawing. 


\section{Measurement of drip loss}

All the samples were weighed after cutting into pieces of similar size. The treated samples were reweighed after marinating and again after thawing. Drip loss was measured after draining the drip from frozen meat during thawing, and calculated as follows:

Drip loss $(\%)=[(w 1-w 2) / w 1] \times 100 ;$ where, $w 1=$ meat weight before preservation and $\mathrm{w} 2$ = meat weight after preservation.

\section{Measurement of water-holding capacity}

Muscle water-holding capacity (WHC) was determined by the filter paper press method (Grau and Hamm, 1953). Each piece of meat $\left(1 \times 1 \times 1.5 \mathrm{~cm}^{3}\right)$ was covered with eight sheets of filter paper and pressed with a $12 \mathrm{~kg}$ load for two minutes. The waterholding capacity was calculated as follows:

WHC $(\%)=[1-\{($ meat weight before pressing - meat weight after pressing) (meal weight before pressing $\times$ moisture content in gram) $\}] \times 100$

\section{Measurement of cook loss}

Each meat sample was wrapped in a heat-stable foil paper and kept in water bath at $80^{\circ} \mathrm{C}$ for 30 minutes. The internal temperature was not measured, but from a previous study (Sultana et al., 2008) it was estimated that the optimum internal meat temperature $\left(75-80^{\circ} \mathrm{C}\right)$ would be gained by 30 minutes. Cook loss was calculated after draining the drip coming from the cooked meat, as follows:

Cook loss $(\%)=[(w 2-w 3) / w 2] \times 100 ;$ where, $w 2=$ meat weight before cooking and $w 3$ $=$ meat weight after cooking.

\section{Sensory evaluation}

Three medium-thin slices from each piece of muscle were grilled at medium heat with gas burner for two minutes. The grilled samples were given to 10 trainees and staff of Bangladesh Livestock Research Institute, who were not trained in the sensory analysis of meat. Eight characteristics - general appearance, tenderness, juiciness, flavour, colour, saltiness, acid taste and overall taste - were evaluated on a sevenpoint scale from -3 to +3 (very poor to excellent). Panellists first tasted the untreated meat, and then rinsed out their mouth with water. Then they tasted the treated meat and ranked the two samples.

\section{Statistics}

Means and standard deviation were calculated among samples and the t-test was done for significant differences between control and treated meats.

\section{Results and Discussion}

Treated meat had significantly $(\mathrm{p}<0.05)$ higher moisture content (Table 1$)$. High moisture content after salt bicarbonate marinating was confirmed in beef biceps femoris 
muscle (Sultana et al., 2008). Baublits et al. (2005) got significantly $(\mathrm{p}<0.05)$ increased moisture content in salt-treated raw biceps femoris muscle.

Table 1. Nutrient content of marinating kit treated frozen-thawed raw and cooked meat after one month of preservation

\begin{tabular}{l|c|c|c|c|c|c}
\hline \multirow{2}{*}{$\begin{array}{c}\text { Nutrient } \\
\text { content }\end{array}$} & \multicolumn{3}{|c|}{ Frozen raw meat } & \multicolumn{3}{c}{ Frozen cooked meat } \\
\cline { 2 - 7 } & $\begin{array}{c}\text { Non- } \\
\text { marinated (\%) }\end{array}$ & $\begin{array}{c}\text { Marinated } \\
(\%)\end{array}$ & Significance & $\begin{array}{c}\text { Non- } \\
\text { marinated (\%) }\end{array}$ & $\begin{array}{c}\text { Marinated } \\
(\%)\end{array}$ & Significance \\
\hline Moisture & $75.80 \pm 0.8$ & $77.90 \pm 1.7$ & NS & $65.56 \pm 1.8$ & $68.77 \pm 2.9$ & $*$ \\
Protein & $18.41 \pm 0.2$ & $18.59 \pm 0.5$ & NS & $30.01 \pm 2.4$ & $27.75 \pm 1.2$ & $*$ \\
Fat & $2.4 \pm 0.6$ & $1.9 \pm 0.1$ & NS & $1.9 \pm 0.5$ & $2.2 \pm 0.1$ & NS \\
\hline
\end{tabular}

NS, Non significant, ${ }^{*}, \mathrm{p}<0.05$

After one month of freezing the higher moisture content in treated cooked meat proved that the kit containing salt and bicarbonate preserved meat well in the freezer. The treated raw meat contained a similar amount of protein (Table 1) but the cooked treated meat had significantly $(\mathrm{p}<0.05)$ lower protein content than the control, which maybe resulted from the solubilization of myofibrillar protein due to application of salt and bicarbonate. After solubilization, protein, probably actin and myosin, remained in the raw meats. But moist heat during cooking might have caused the solubilized protein to come out with drip from the treated meat. In Bangladesh, however, traditional meat curry recipes provide the opportunity to consume both meat and drip after cooking, so, there is no chance to lose protein.

The treated samples had higher $\mathrm{pH}$ due to bicarbonate in marinating kit. Similar increases in $\mathrm{pH}$ have been reported by others after phosphate and bicarbonate were applied to meat (Robbins et al., 2003; Sindelar et al., 2003; Murphy and Zerby, 2004).

Compared with the control meat, treated meat lost less drip $(\mathrm{p}<0.05)$ during freezing (Fig 2). Higher water-holding capacity $(\mathrm{p}<0.05)$ was found in treated meat (Fig 3). Sheard and Tali (2004) reported lower drip loss in pork loin treated with salt and bicarbonate. Sen et al. (2005) also reported higher WHC in bicarbonate - salt treated broiler breast meat than phosphate-treated meat. Hamm (1970), explained that chloride in salt solution induces swelling in myofibrils and makes higher water retention within the protein network. Therefore, the high $\mathrm{pH}$ and salt concentration in meat were responsible for high retention of water and lower drip loss in treated meat. High water-holding capacity in treated meat obviously caused lower cook loss in treated meat (Fig. 4). A wide range of results were reported (Brotsky, 1976; Babdji et al., 1982; Froning and Sackett, 1985) that marinating with salt solution not only increases WHC of meat, but reduces cook loss and increases meat juiciness. Bright cherry red colour (Fig. 5) was observed in treated raw meat, whereas the control meat showed dull or pale red colour because of losing drip and higher oxidation compare to the treated meat. The ascorbic acid might play a role as an antioxidant and colour retainer in treated meat. 


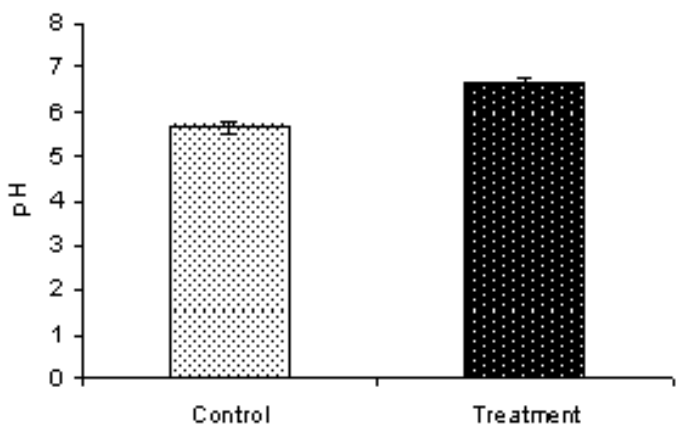

Fig. 1. $\mathrm{pH}$ in marinated meat after one month of freezing

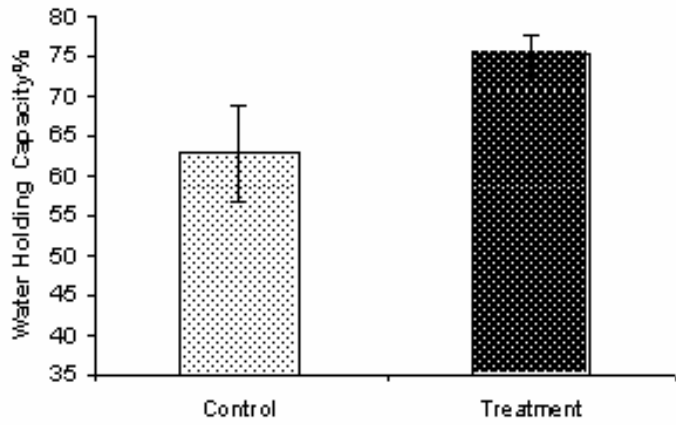

Fig. 3. Water-holding capacity of marinated meat after one month of freezing

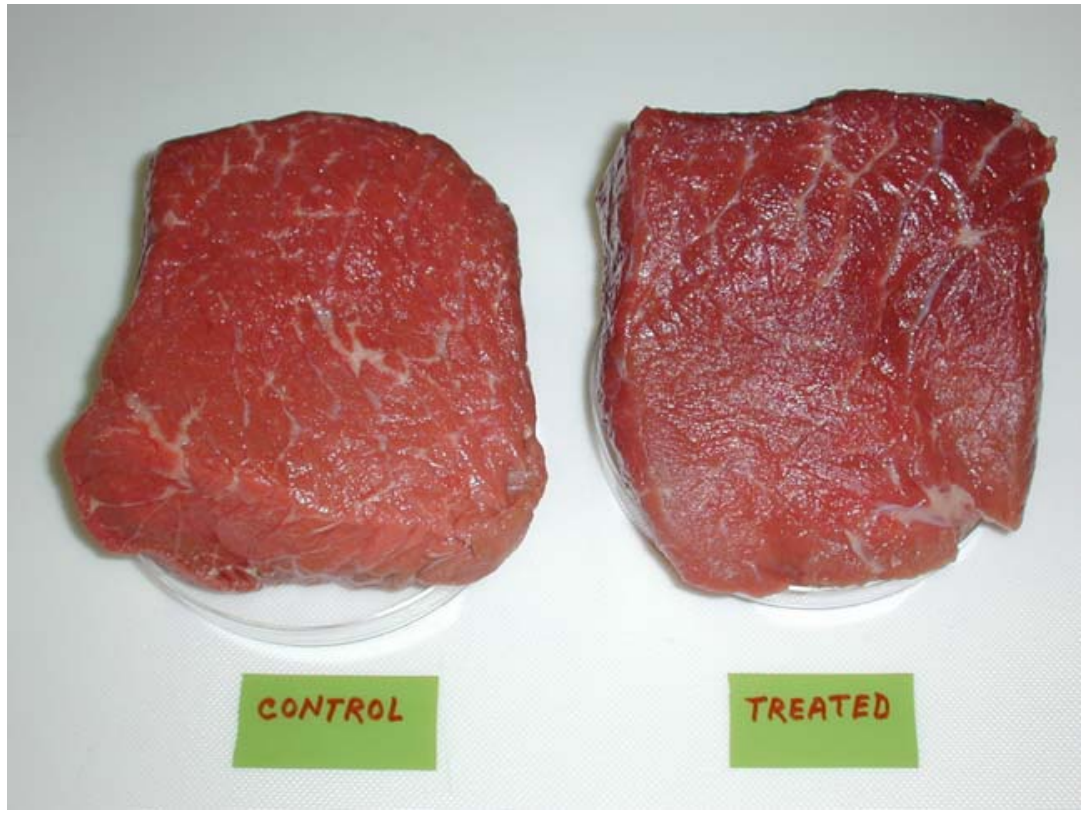

Fig. 5. Appearance of marinated raw meat after one month of freezing

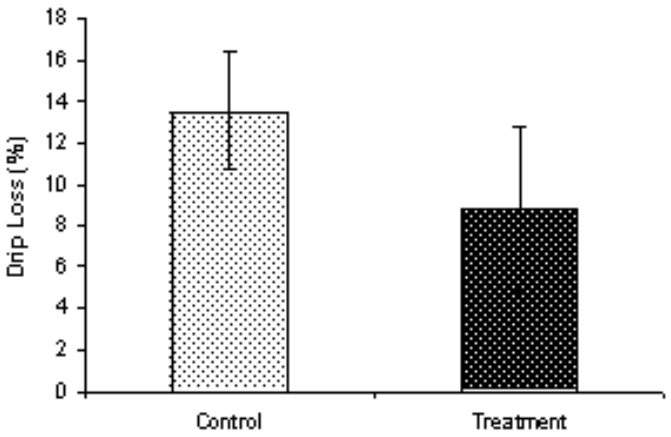

Fig. 2. Effect of marinating on the amount of drip in meat after one month of freezing

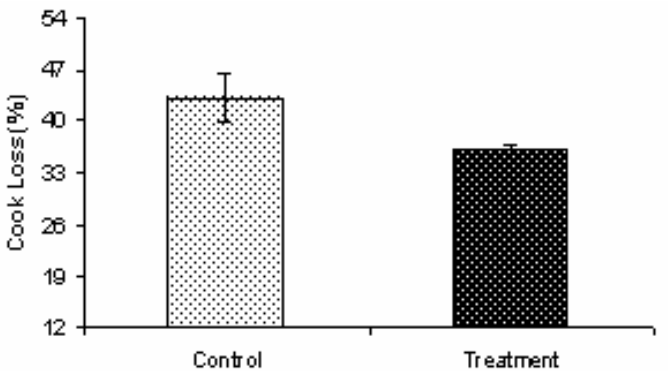

Fig. 4. Cook loss (\%) of marinated meat after one month of freezing 
In the sensory test, the panellists found significantly higher value for general appearance $(p<0.01)$, flavour $(p<0.05)$, colour $(p<0.05)$, tenderness $(p<0.01)$, juiciness $(p<0.01)$ saltiness $(p<0.01)$ and overall acceptability $(p<0.91)$ (Fig. 6). Another study reported the same results in beef (Sultana, A. et al, 2008). Baublits et al. (2005) reported that the addition of sodium chloride in beef biceps femoris gave higher tenderness ratings than control. Kauffman et al. (1998) got improved flavour in hot boned loins from gilts when they injected sodium bicarbonate and salt. Lower drip loss $(p<0.05)$, cook loss $(p<0.01)$ and higher water-holding capacity $(p<0.05)$ in treated meat might be responsible for the higher juiciness $(\mathrm{p}<0.01)$.

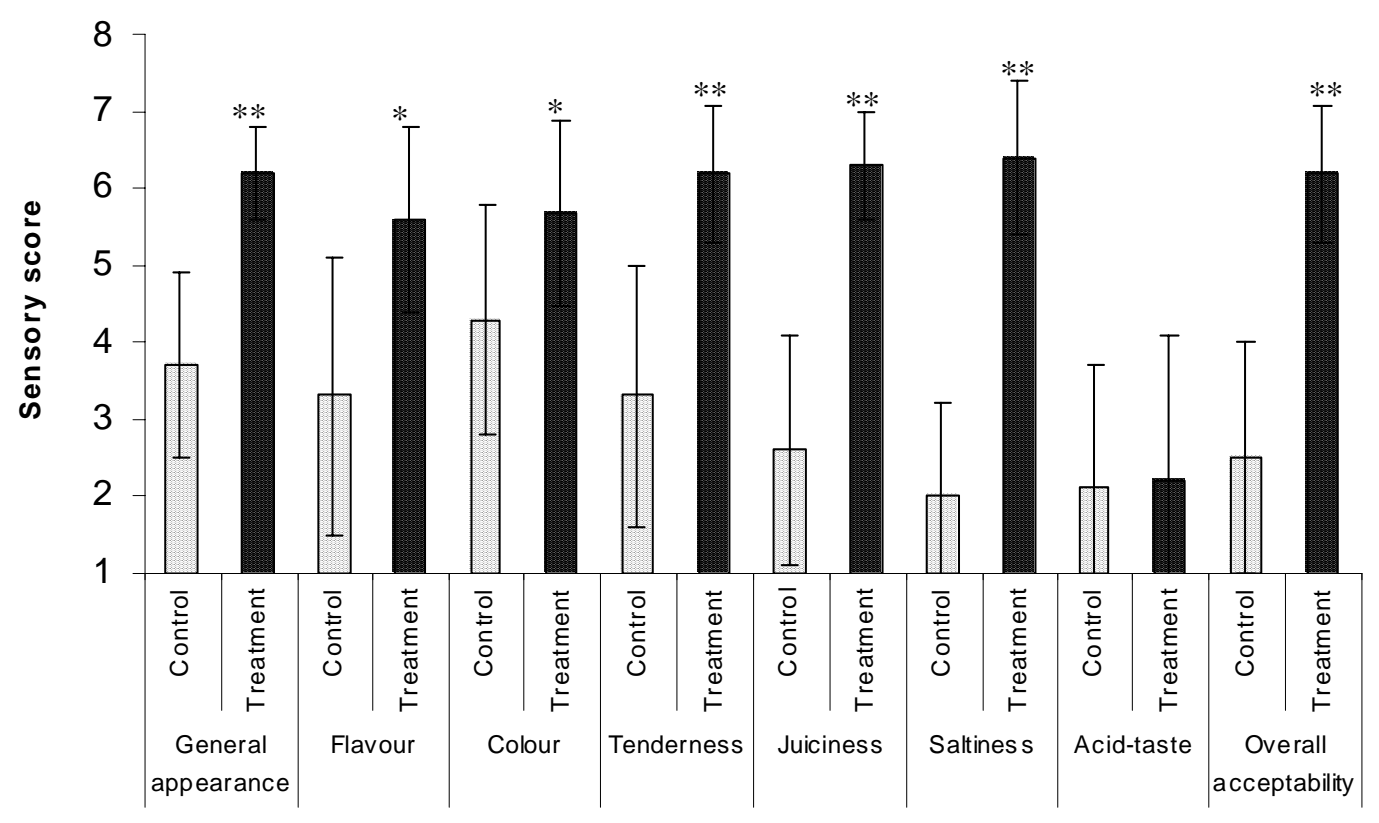

Fig. 6. Sensory performance of marinated meat after one month of freezing

\section{Conclusions}

Use of marinating kits may be one of the methods for preventing quality deterioration of beef during freezing and simultaneously for producing higher quality, more convenient meat cuts from unpalatable, tough cuts of beef carcass both for consumers at household level and for beef processing industry. Additionally, the hotels, restaurants, hospitals and fast food shops, which are in need of convenient high quality "ready-to-cook" meat, might use such kit. However, further study is needed to identify expiration or validation of tasty kit for merchandising. It is also necessary to search the efficacy of the kit for chicken, chevron, buffalo, mutton and lamb. 


\section{References}

AOAC 1980: Association of Official Analytical Chemists. Horwitz N (Ed.), Official Methods of Analysis, Association of Official Analytical Chemists, 13th Edn., Washington, DC pp. 957.

Babdji AS, Froning GW, Ngoka DA 1982: The effect of short-term tumbling and salting on the quality of turkey breast muscle. Poultry Science 61 300-303.

Baublits RT, Pohlman FW, Brown Jr AH, Jonson ZB 2005: Effects of sodium chloride, phosphate type and concentration, and pump rate on beef biceps femoris quality and sensory characteristics. Meat Science 70 205-214.

Brotsky E 1976: Automatic injection of chicken parts with polyphosphate. Poultry Science 55 653-660.

Farouk MM, Wieliczko KJ, Merts I 2003: Ultra-fast freezing and low storage temperatures are not necessary to maintain the functional properties of manufacturing beef. Meat Science 66 171-179.

Farouk, MM, Swan JE 1998: Effect of rigor temperature and frozen storage on functional properties of hot-boned manufacturing beef. Meat Science 49 233-247.

Froning GW, Sackett B 1985: Effect of salt and phosphates during tumbling of turkey breast muscle on meat characteristics. Poultry Science 64 1328-1333.

Gary AS, Chris RC 2007: Nebaraska Beef Cattle Report, The Board of Regents of the University of Nebraska.

Grau R, Hamm G. 1953: Eine Einfache Methode zur Bestimmung der Wasserbindung in Muskel. Die Naturwissenschaften, 40 277-259.

Hamm R 1970: Interactions between phosphates and meat proteins. In: Symposium: phosphates in food processing (Eds. JM deMan and P Melnychyn), AVI Publishing Co., Westport, Conn. pp. 65-82.

Honikel KO, Kim CJ, Hamm R, Roncales P 1986: Sarcomere shortening of prerigor muscles and its influence on drip loss. Meat Science 16 267-282.

Kauffman RG, Vanlacck RLJM, Russel RL, Pospiech E, Cornelius CA, Suckow CE, Greaser ML 1998: Can pale, soft, exudative pork be prevented by postmortem sodium bicarbonate injection? Journal of Animal Science 76 3010-3015.

Murphy MA, Zerby HN 2004: Prerigor infusion of lamb with sodium chloride, phosphate and dextrose solutions to improve tenderness. Meat Science 66 343-349.

Robbins K, Jensen J, Homco-Ryan C, McKeith FK, Brewer MS 2003: Dietary vitamin E supplementation effects on the color and sensory characteristics of enhanced beef steaks. Meat Science 64 279-285.

Savell JW, Smith GC 2000: Laboratory manual for meat science (7th ed.). Boston, MA: American Press.

Sen AR, Naveena BM, Muthukurnar M, Babji Y, Murthy TR 2005: Effect of chilling, polyphosphate and bicarbonate on quality characteristics of broiler breast meat. British Poultry Science 46: 451-456. 
Sheard PR, Tali A 2004: Injection of salt, tripolyphosphate and bicarbonate marinade solutions to improve the yield and tenderness of cooked pork loin. Meat Science 68 305-311.

Sindelar JJ, Prochaska F, Britt J, Smith GL, Miller RK, Templeman R., Osburn WN 2003: Strategies to eliminate atypical flavours and aromas in sow loins. 1. Optimization of sodium tripolyphosphate, sodium bicarbonate, and injection level. Meat Science 65 1211-1222.

Sullivan GA, Calkins CR 2007: Ranking Beef Muscles for Warner-Bratzler Shear Force and Trained Sensory Panel Ratings, The Board of Regents of the University of Nebraska. Nebraska Beef Report pp. 94.

Sultana A, Nakanishi A, Roy BC, Mizunoya W, Tatsumi R, Ito T, Tabata S, Rashid H, Katayama, S, Ikeuchi Y 2008: Quality Improvement of Frozen and Chilled Beef biceps femoris with the Application of Salt-bicarbonate Solution. Asian- Australasian Journal of Animal Sciences 21 903-911. 